\section{Heterotopic heart transplantation: A direct pulmonary artery anastomosis technique}

To the Editor:

In the initial clinical experience with heterotopic heart transplantation reported by Barnard and Losman, ${ }^{1}$ the pulmonary artery (PA) was anastomosed to the right atrium. Because of grave arrhythmias of the native heart in some patients, this technique was modified. Thereafter, the donor PA was connected to the recipient PA by interposition of a Dacron conduit. ${ }^{2}$

To prevent the potential complications of a PA prosthetic conduit and also to avoid the heavy adhesions involving the recipient $\mathrm{PA}$, we designed a new technique that allowed us to connect the donor PA to the recipient right PA.

In February 1993 we used this technique to a 43-year-old man with end-stage ischemic cardiomyopathy. That patient had had left ventricular aneurysmectomy 1 year before. He had severe pulmonary hypertension, and the calculated pulmonary vascular resistance was 7 Wood units.

To accomplish the direct PA anastomosis, we transected the recipient superior vena cava (SVC) near the right atrium, sutured its lower stump, and laterally mobilized its upper stump, which exposed the right PA. A left atrial incision was made anteriorly to the right superior pulmonary vein and extended upward in the interatrial groove. The donor heart was placed in the right side of the chest and the two left atria were sutured in a position that allowed the donor PA to easily reach the recipient right PA. The PA anastomosis was followed by the anastomosis of the recipient upper SVC stump to the donor SVC. Another right atrial connection was made near the recipient inferior vena cava, allowing the lower body venous return of the recipient to reach the donor right atrium. The donor ascending aorta, which was long, was anastomosed as distally as possible in the recipient ascending aorta to ease the access to the PA anastomosis in case of bleeding.

This patient did very well after the operation. The systolic PA pressure dropped from the preoperative level of $85 \mathrm{~mm} \mathrm{Hg}$ to $50 \mathrm{~mm} \mathrm{Hg}$ when he left the intesive care unit. In the 6-month follow-up study the systolic PA pressure had regressed to $30 \mathrm{~mm}$ $\mathrm{Hg}$ and the angiogram (Fig. 1) showed good anatomic and functional features.

The possible advantages of this method are as follows: (1) The theoretic complications of a PA prosthetic graft, such as infection, thrombosis, and fibrosis tissue formation, are prevented; (2) the problems of freeing tough adhesions over the recipient PA in reoperations are avoided; and (3) endomyocardial biopsy is facilitated because the SVC anastomosis leads the byoptome forceps easily to the donor right venticle.

José Pedro Da Silva, MD

Marcelo Matos Cascudo, MD

José Francisco Baumgratz, $M D$

José Henrique Andrade Vila, MD

Mohamed Wafae Filho, MD

Dionisio Otavio Bentes de Carvalho Neto, $M D$

Luciana Da Fonseca, $M D$

Division of Cardiovascular Surgery

Hospital Beneficencia Portuguêsa

São Paulo, Brazil

\section{R E F ER E N CES}

1. Barnard CN, Losman JG. Left ventricular bypass. S Afr Med J 1975;49:303-12

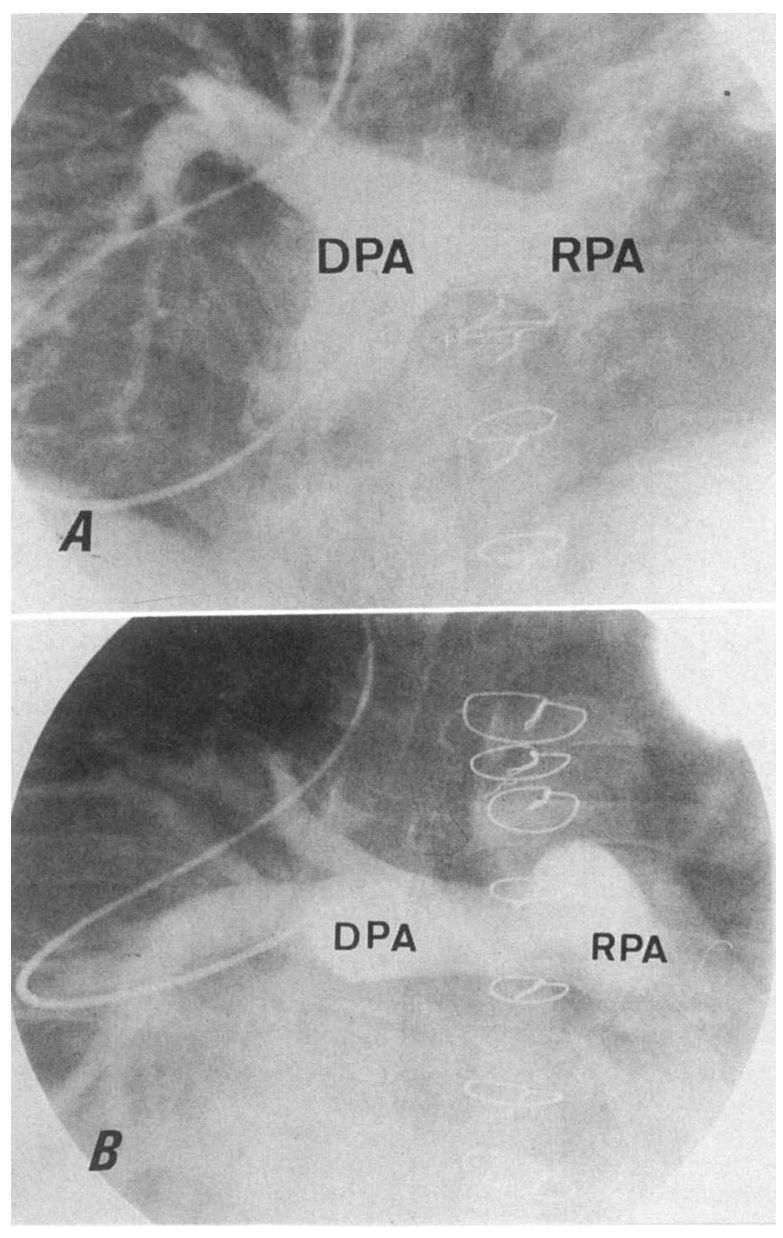

Fig. 1. Pulmonary cineangiograms 6 months after the operation showing the donor PA connected to the recipient right PA. A, Frontal view with cranial tilt. B, Frontal view. $D P A$, Donor pulmonary artery; $R P A$, recipient pulmonary artery.

2. Novitzky D, Cooper DKC, Barnard CN. The surgical technique of heterotopic heart transplantation. Ann Thorac Surg 1983;36:476-82.

\section{Continuous monitoring of coronary sinus oxygen saturation during warm heart surgery}

\section{To the Editor:}

Warm heart surgery has been proposed by Lichtenstein and his colleagues ${ }^{1}$ to be the alternative strategy to the conventional hypothermic cardiac arrest technique during cardiac operations. That modality of myocardial protection is said to maintain myocardial preservation by eliminating the period of ischemia, avoiding the side effects of hypothermia and abolishing reperfusion injury. ${ }^{2}$ However, because the normothermic heart is far more vulnerable to anaerobic conditions than is the hypo- 